\title{
Double-hit or dual expression of MYC and BCL2 in primary cutaneous large B-cell lymphomas
}

\author{
Sarah Menguy ${ }^{1,2} \cdot$ Eric Frison $^{3} \cdot$ Martina Prochazkova-Carlotti $^{1} \cdot$ Stephane Dalle $^{4} \cdot$ Olivier Dereure $^{5}$.

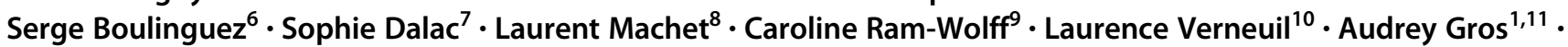 \\ Béatrice Vergier $^{1,2} \cdot$ Marie Beylot-Barry ${ }^{1,12} \cdot$ Jean-Philippe Merlio $\mathbb{I}^{1,11} \cdot$ Anne Pham-Ledard ${ }^{1,12}$
}

Received: 8 November 2017 / Revised: 29 January 2018 / Accepted: 29 January 2018 / Published online: 26 March 2018

(c) United States \& Canadian Academy of Pathology 2018

\begin{abstract}
In nodal diffuse large B-cell lymphoma, the search for double-hit with $M Y C$ and BCL2 and/or BCL6 rearrangements or for dual expression of BCL2 and MYC defines subgroups of patients with altered prognosis that has not been evaluated in primary cutaneous large B-cell lymphoma. Our objectives were to assess the double-hit and dual expressor status in a cohort of 44 patients with primary cutaneous large B-cell lymphoma according to the histological subtype and to evaluate their prognosis relevance. The 44 cases defined by the presence of more than $80 \%$ of large B-cells in the dermis corresponded to 21 primary cutaneous follicle centre lymphoma with large cell morphology and 23 primary cutaneous diffuse large B-cell lymphoma, leg type. Thirty-one cases (70\%) expressed BCL2 and 29 (66\%) expressed MYC. Dual expressor profile was observed in 25 cases (57\%) of either subtypes ( $n=6$ or $n=19$, respectively). Only one primary cutaneous follicle centre lymphoma, large-cell case had a double-hit status $(2 \%)$. Specific survival was significantly worse in primary cutaneous diffuse large B-cell lymphoma, leg type than in primary cutaneous follicle centre lymphoma, large cell $(p=0.021)$ and for the dual expressor primary cutaneous large B-cell lymphoma group $(p=0.030)$. Both overall survival and specific survival were worse for patients belonging to the dual expressor primary cutaneous diffuse large B-cell lymphoma, leg type subgroup ( $p=0.001$ and $p=0.046$, respectively). Expression of either MYC and/or BCL2 negatively impacted overall survival ( $p=0.017$ and $p=0.018$ respectively). As the differential diagnosis between primary cutaneous follicle centre lymphoma, large cell and primary cutaneous diffuse large B-cell lymphoma, leg type has a major impact on prognosis, dual-expression of BCL2 and MYC may represent a new diagnostic criterion for primary cutaneous diffuse large B-cell lymphoma, leg type subtype and further identifies patients with impaired survival. Finally, the double-hit assessment does not appear clinically relevant in primary cutaneous large B-cell lymphoma.
\end{abstract}

Jean-Philippe Merlio

jp.merlio@u-bordeaux.fr

1 INSERM U1053, University of Bordeaux, 33000 Bordeaux, France

2 Department of Pathology, CHU de Bordeaux, 33600 Pessac, France

3 ISPED, CHU and University of Bordeaux, 33000 Bordeaux, France

4 Department of Dermatology, CHU Lyon HCL-GH Sud, Pierre Benite Lyon Cedex, 69495 Pierre Benite, France

5 Department of Dermatology, Hôpital Saint Eloi, University of Montpellier and INSERM 1058, 34295 Montpellier, France

6 Department of Dermatology, Hôpital Larrey, CHU de Toulouse,
31059 Toulouse 9, France

7 Department of Dermatology, Complexe du Bocage, CHU de Dijon, 21079 Dijon, France

8 Department of Dermatology, Hôpital Trousseau, CHU de Tours, 37044 Tours 9, France

9 Department of Dermatology, Hôpital Saint-Louis, APHP, 75475 Paris 10, France

10 Department of Dermatology, Hôpital Clemenceau, CHU de Caen, 14033 Caen, France

11 Tumor Bank and Tumor Biology Laboratory, CHU de Bordeaux, 33600 Pessac, France

12 Department of Dermatology, CHU de Bordeaux, 33000 Bordeau, France 


\section{Introduction}

Primary cutaneous B-cell lymphoma have been divided into the 3 following groups: primary cutaneous marginal zone lymphoma, primary cutaneous follicle centre lymphoma and primary cutaneous diffuse large B-cell lymphoma, leg type $[1,2]$. Differential diagnosis between these entities is crucial to adapt the therapy. Primary cutaneous marginal zone lymphoma and primary cutaneous follicle centre lymphoma are mostly small B-cell lymphomas forming unique or multiple skin lesions. A conservative treatment with excision and/or radiotherapy for localized disease, or Rituximab for diffuse skin involvement permit to achieve complete response with a 95\% 5-year survival despite frequent relapses [3]. On the other hand, primary cutaneous diffuse large B-cell lymphoma, leg type displays an aggressive behavior despite therapeutic improvement by the combination of rituximab and age-adjusted chemotherapy reaching a 74\% 5-year overall survival [4]. In these patients, refractory disease or relapse are associated with a high risk of secondary extracutaneous spreading as opposed to primary cutaneous follicle centre lymphoma where relapse may occur without impairing prognosis $[4,5]$. Question still remains whether cutaneous large B-cell lymphomas with borderline features between primary cutaneous follicle centre lymphoma and primary cutaneous diffuse large B-cell lymphoma, leg-type could define a distinct category [6-8]. Indeed, the 2005 WHO/EORTC classification individualized a primary cutaneous large B-cell lymphoma "other" subgroup for rare cases not belonging to the two categories [1]. Conversely, the most recent WHO classification considered these cases as a large cell and diffuse variant of primary cutaneous follicle centre lymphoma on the basis of their clinical features and favorable outcome [2, 9]. For the pathologist, the accurate classification of primary cutaneous B-cell lymphoma displaying diffuse pattern and predominant large cell morphology is therefore an important challenge and there is an obvious need for evaluating new diagnostic criteria. Moreover, a study of 161 cases of primary cutaneous B-cell lymphoma other than primary cutaneous marginal zone lymphoma individualized 40 cases $(30 \%)$ corresponding to primary cutaneous large B-cell lymphoma not otherwise specified with an intermediate behavior between primary cutaneous follicle centre lymphoma and primary cutaneous diffuse large B-cell lymphoma, leg type according to their cell of origin profile determined by the immunohistochemical Hans' algorithm [6, 10].

Indeed, the hierarchical determination of CD10, BCL6 and MUM1 expression [10] is compulsory in nodal diffuse large B cell lymphoma as the non-germinal centre subtype also called activated B-cell displays more aggressive clinical and evolutive features than the germinal centre subtype $[11,12]$. In primary cutaneous Bcell lymphoma, gene expression profiling has shown that primary cutaneous follicle centre lymphoma derives from germinal centre cells while most primary cutaneous diffuse large B-cell lymphoma, leg type cases are of nongerminal centre subtype [13]. However, the Hans' algorithm may not permit the differential diagnosis as nongerminal centre type of primary cutaneous follicle centre lymphoma with large cell morphology or germinal centre type of primary cutaneous diffuse large B-cell lymphoma, leg type cases have been reported $[6,14,15]$. Indeed, the WHO classification textbook points to some limitations in using the immunohistochemical algorithm for primary cutaneous B-cell lymphoma classification as CD10 expression may be lost in primary cutaneous follicle centre lymphoma, large cell while BCL6 may be expressed as frequently in primary cutaneous diffuse large B-cell lymphoma, leg-type as in primary cutaneous follicle centre lymphoma [2, 16]. Among primary cutaneous B-cell lymphoma with large cell morphology, the combined BCL2 and MUM1 expression together with a high proliferative index as assessed by Ki-67 immunostaining have been employed as diagnostic features of primary cutaneous diffuse large B-cell lymphoma, leg type $[16,17]$. TP63 expression and the MYD88 $8^{\mathrm{L} 265 \mathrm{P}}$ mutation have also been proposed as criteria for primary cutaneous diffuse large B-cell lymphoma, leg-type diagnosis as they are not present in primary cutaneous follicle centre lymphoma, large-cell [18, 19].

Interestingly, diffuse large B-cell lymphoma with double-hits involving $M Y C$ and $B C L 2$ and/or $B C L 6$ rearrangement are now classified in the high grade B-cell lymphomas category according to their inferior survival [2, 20-22]. The co-expression of BCL2 and MYC in DLBCL without double-hit is now referred to as dual expressor diffuse large B-cell lymphoma, a subgroup more frequently observed in the non-germinal centre-type diffuse large B-cell lymphoma [23-25]. Patients with dual expressor-diffuse large B-cell lymphoma have an altered prognosis and an increased risk of central nervous system relapse [25-27]. The parallel evaluation of double-hit and dual expression has not been so far evaluated in primary cutaneous B-cell lymphoma with large cell morphology.

Therefore, we retrieved in the French Study group on cutaneous lymphoma database a series of typical cases corresponding to either primary cutaneous follicle centre lymphoma, large cell or to primary cutaneous diffuse large B-cell lymphoma, leg type. Our goal was to determine if double-hit or dual expressor status correlates with the histological subtype and may identify a subgroup of patients with specific evolutive features. 


\section{Methods}

\section{Patient selection}

Primary cutaneous B-cell lymphoma containing at least $80 \%$ large tumoral cells were prospectively reviewed and included between 1993 and 2016 in the database of the French Study group on cutaneous lymphomas between 1993 and 2016. We retrieved cases on the basis of complete clinical record and available formalin-fixed paraffinembedded skin biopsy to perform fluorescent in situ hybridization (FISH) and immunochemical techniques. Diagnoses were reevaluated according to the 2016 WHO classification criteria which does not retain an "other" category to finalize the primary diagnosis into two separate categories [2]. Primary cutaneous diffuse large B-cell lymphoma, leg type exhibited a diffuse pattern with immunoblastic and centroblastic features with strong expression BCL2 and MUM1. The presence of the MYD $88^{L 265 P}$ mutation was also used as a diagnostic criterion [18]. Primary cutaneous follicle centre lymphoma, large-cell were selected as diffuse and/or nodular infiltration by large cells with centroblastic and/or centrocytic features associated with low expression or negativity for BCL2 and MUM1. Six cases of primary cutaneous diffuse large B-cell lymphoma, leg-type have been already investigated by FISH by Pham-Ledard et al. [28] and 35 cases for MYD88 status by Menguy et al. [18].

International staging criteria for B-cell cutaneous lymphomas were used and secondary cutaneous lymphoma excluded [29]. The study was performed after registration of absence of opposition according to the guidelines of the French Bioethical law for retrospective non interventional research studies.

\section{Immunohistochemistry}

Automated immunostaining was performed on formalinfixed paraffin-embedded slides (Bond Max, Leica, Nanterre, France). We tested BCL2 (clone 124, DAKO, Les Ulis, France), BCL2 (clone E17, Gene Tex, Irvine, CA), MUM1 (clone MUM1p, DAKO), BCL6 (clone PGB6P, DAKO), Ki-67 (clone MM1, Leica Biosystems, Newcastle Ltd, UK), and MYC (clone Y69, Epitomics, Burlingame, CA). BCL2 (clone 124), BCL6, Ki-67, and MUM1 immunostainings were part of the original diagnosis criteria. MYC immunochemistry was performed during 2016 and BCL2 clone E17 during June 2017. BCL2 and MUM1 were considered positive if more than $50 \%$ of the cells were stained. A $40 \%$ positive cells threshold was used for MYC according to criteria used in diffuse large B-cell lymphoma [2, 23]. Each immunohistochemical staining was independently interpreted by 3 pathologists (SM, BV, and JPM). In case of discrepancy, slides were reviewed together to reach agreement. The immunohistochemical scoring was performed without knowledge of FISH results or patient outcome.

\section{Interphase fluorescence in situ hybridization (FISH)}

Such analysis was performed in June and July 2017, on formalin-fixed paraffin-embedded slides as reported previously [28]. Hybridization was conducted with labeled probes for $B C L 2, B C L 6$, and MYC (FISH DNA split signal, DAKO). Slides were analyzed with a fluorescence microscope (Imager Z2, Zeiss, Jena, Germany) by two independent observers (SM and JPM). In case of discrepancy, slides were reviewed together to reach agreement. Images were collected using workstation equipped with Isis software (Metasystems, Altlussheim, Germany). FISH patterns were recorded by analyzing 100 non-overlapped tumor cell nuclei and abnormal patterns were taken into account above a $10 \%$ threshold. We investigated gene breakpoint with split of red and green signal and copy number variation such as extra copy (more than 2 fusions pattern). Low copy-number gain was evaluated as more than 3 copies and less than 6 copies and amplification as more than or equal to 6 copies.

\section{MYD88 status determination}

The MYD88 status was assessed by allele specific real time PCR as reported elsewhere [30]. The MYD88 status was reported in 35 patients by Menguy et al. [18] and determined for 9 patients of the present series.

\section{Statistical analysis}

Quantitative characteristics were described by median and range, and qualitative characteristics were described by number and frequency. Comparisons of qualitative characteristics between subgroups of patients were performed using Fisher's exact test. Progression free survival was calculated as the time between the date of diagnosis and the date of recurrence or death. Overall survival was determined from the date of diagnosis to the date of death of any cause. Specific survival duration was calculated from diagnosis to date of disease-related death, with patients whose death was unrelated to lymphoma considered censored at death time. Both overall survival and specific survival were evaluated considering the advanced age of the patients, especially those with primary cutaneous diffuse large B-cell lymphoma, leg type. The administrative date of end of followup was set to 1 August 2017. Survival curves were plotted using the Kaplan-Meier method and compared using the log-rank test for each prognostic factor (diagnosis type, dual expressor status, double-hit status). A two-sided $p<0.05$ was considered significant. Statistical analysis was 
performed using MedCalc software, version 12.4.0 (Ostend, Belgium).

\section{Results}

\section{Cohort}

The multicentre study analyzed the features of a series of 44 patients with primary cutaneous large B-cell lymphoma defined by the presence of more than 80 per cent large cells. Patients with primary cutaneous follicle centre lymphoma, large cell $(n=21)$ were 5 women $(24 \%)$ and 16 men $(76 \%)$ with median age at diagnosis of 64 years (range: 42-86). Patients with primary cutaneous diffuse large B-cell lymphoma, leg type $(n=23)$ were 15 women $(65 \%)$ and 8 men $(35 \%)$ with a median age at diagnosis of 82 years (range: 61-95).

In the 21 patients with primary cutaneous follicle centre lymphoma, large cell, nine $(43 \%)$ were at T1 stage, 10 $(48 \%)$ at T2 stage and $2(9 \%)$ at T3 stage. The most frequent localization was head and neck $(52 \%, n=11)$. The other localizations were trunk $(38 \%, n=8)$, leg $(5 \%, n=1)$ and $\operatorname{arm}(5 \%, n=1)$.

Among the 23 patients with primary cutaneous diffuse large B-cell lymphoma, leg type, six (26\%) had a solitary lesion (T1), 15 (65\%) had a regional skin involvement (T2) and $2(9 \%)$ had generalized skin involvement (T3). The most frequent site was the leg $(78 \%, n=18)$. The other sites were arms $(9 \% ; n=2)$, trunk $(9 \%, n=2)$ and head and neck $(4 \%, n=1)$.

All patients had primary cutaneous lymphoma and the initial staging including computed tomography scan was negative. Clinical data are summarized in Table 1.

\section{Histological features}

Among the 21 primary cutaneous follicle centre lymphoma, large cell cases, 10 cases (48\%) showed a diffuse pattern, 5 cases $(24 \%)$ a nodular and diffuse pattern and 6 cases $(28 \%)$ a nodular pattern (Table 2). Among the 23 primary cutaneous diffuse large B-cell lymphoma, leg type cases, 13 cases $(57 \%)$ had diffuse pattern and 10 cases $(43 \%)$ a nodular and diffuse pattern. Concerning cytomorphology, the majority of cells of 4 cases (19\%) out of 21 primary cutaneous follicle centre lymphoma, large cell had centroblastic appearance, 8 cases $(38 \%)$ a spindle cell aspect and 9 cases $(43 \%)$ contained a mixture of centroblasts and large centrocytes (Fig. 1a). Concerning the 23 primary cutaneous diffuse large B-cell lymphoma, leg type cases, 10 cases (44\%) had an immunoblastic morphology with a prominent nucleolus and 13 cases $(56 \%)$ contained a mixture of immunoblasts and centroblasts (Fig. 1b).
Table 1 Clinical features at baseline, and follow-up of patients with primary cutaneous large B-cell lymphoma, diagnosed between 1993 and 2016-French Study group on cutaneous lymphoma database, France $(n=44)$

\begin{tabular}{|c|c|c|}
\hline & $\begin{array}{l}\text { Primary cutaneous } \\
\text { follicle centre cell } \\
\text { lymphoma, large cell } \\
(n=21)\end{array}$ & $\begin{array}{l}\text { Primary cutaneous } \\
\text { diffuse large B-cell } \\
\text { lymphoma, leg type } \\
(n=23)\end{array}$ \\
\hline \multicolumn{3}{|l|}{ Baseline characteristics } \\
\hline $\begin{array}{l}\text { Age, median } \\
\text { (range), years }\end{array}$ & $64(42-86)$ & $82(61-95)$ \\
\hline Male, No (\%) & $16(76)$ & $8(35)$ \\
\hline Female, No (\%) & $5(24)$ & $15(65)$ \\
\hline \multicolumn{3}{|l|}{ Location, No (\%) } \\
\hline Leg & $1(5)$ & $18(78)$ \\
\hline Arm & $1(5)$ & $2(9)$ \\
\hline Head and neck & $11(52)$ & $1(4)$ \\
\hline Trunk & $8(38)$ & $2(9)$ \\
\hline \multicolumn{3}{|c|}{ Tumor node metastasis stage, No (\%) } \\
\hline $\mathrm{T} 1$ & $9(43)$ & $6(26)$ \\
\hline $\mathrm{T} 2$ & $10(48)$ & $15(65)$ \\
\hline $\mathrm{T} 3$ & $2(9)$ & $2(9)$ \\
\hline $\begin{array}{l}\text { Cutaneous relapse, } \\
\text { No }(\%)\end{array}$ & $9(43)$ & $9(39)$ \\
\hline $\begin{array}{r}\text { Extra cutaneous } \\
\text { spreading, No }(\%)\end{array}$ & $2(9)$ & $6(26)$ \\
\hline \multicolumn{3}{|l|}{ Survival outcome } \\
\hline $\begin{array}{l}\text { Median overall } \\
\text { survival, months }\end{array}$ & & 46 \\
\hline $\begin{array}{l}\text { Median } \\
\text { progression free } \\
\text { survival, months }\end{array}$ & 131 & 32 \\
\hline
\end{tabular}

In the 21 primary cutaneous follicle centre lymphoma, large cell cases, all but one (5\%) were negative for MUM1. BCL2 was found expressed in 6 cases (29\%). In 12 BCL2negative cases according to the anti-BCL2 clone 124 immunostaining, a second round of immunostaining for BCL2 was performed with the clone E17 and 2 cases were then considered positive. Altogether using both anti-BCL2 antibodies, 8 cases (38\%) were considered BCL2 positive. Ten cases (48\%) expressed MYC above the $40 \%$ threshold. All cases (100\%) were positive for BCL6. The mean of proliferation index Ki-67 was $79 \%$.

In the 23 primary cutaneous diffuse large B-cell lymphoma, leg type cases, BCL2 and MUM1 expression was a diagnostic feature used for inclusion (100\%) (Fig. 1c). Nineteen $(83 \%)$ of 23 primary cutaneous diffuse large Bcell lymphoma, leg type cases expressed MYC (Fig. 1d). Twenty cases $(87 \%)$ were positive for BCL6. The mean of proliferation index Ki-67 was $86 \%$.

There was a significant association between BCL2 and MYC expression $(p=0.003)$. Expression of either MYC 
Table 2 Baseline morphological features, immunohistochemical profile and cytogenetic data of patients with primary cutaneous large B cell lymphoma, diagnosed between 1993 and 2016-French Group of Cutaneous Lymphoma database, France $(n=44)$

BCL2 expression by $>50 \%$

cells, No $(\%)$

CMYC expression by $>40 \%$ cells, No (\%)

MUM1 expression by $>50 \%$ cells, No (\%)

BCL6 expression by $>50 \%$ cells, No (\%)

Mean proliferation index $\mathrm{Ki}$ $67(\%)$

Dual expression of MYC/

BCL2, No (\%)

FISH analysis

$B C L 2$ translocation, No (\%)

BCL6 translocation, No (\%)

$C M Y C$ translocation, No (\%)

BCL2 extra copy, No (\%)

BCL6 extra copy, No (\%)

CMYC extra copy, No (\%)

Double-Hit, No (\%)

Dual expression + double-hit, No $(\%)$

MYD88 mutation, No (\%)
Primary cutaneous follicle centre

lymphoma, large cell $(n=21)$

$10(48)$

5 (24)

$6(28)$

4 (19)

8 (38)

$9(43)$

$0(0)$

$0(0)$

$8(38)$

$23(100)$

Primary cutaneous diffuse large Bcell lymphoma, leg type $(n=23)$

13 (57)

$10(43)$

$0(0)$

$0(0)$

$0(0)$

$0(0)$

10 (44)

13 (56)

$10(48)$

$1(5)$

$23(100)$

$21(100)$

79

86

$6(29)$

19 (83)

$0(0)$

0 (0)

$1(5)$

4 (18)

1 (5)

1 (5)

0 (0)

4 (18)

0 (0)

3 (14)

1 (5)

0 (0)

$0(0)$

$0(0)$

1 (5)

$16(70)$ or BCL2 was significantly associated with the diagnosis of primary cutaneous diffuse large B-cell lymphoma, leg type ( $p=0.025, p<0.001$ respectively). Out of 29 cases which expressed MYC, 10 cases (34\%) corresponded to primary cutaneous follicle centre lymphoma, large cell and 19 cases $(66 \%)$ to primary cutaneous diffuse large B-cell lymphoma, leg type. Among the 31 cases which expressed BCL2, 8 cases $(26 \%)$ corresponded to primary cutaneous follicle centre lymphoma, large cell and 23 cases $(74 \%)$ to primary cutaneous diffuse large B-cell lymphoma, leg type.
In the entire cohort $(n=44)$, the 25 dual-expressor cases $(57 \%)$ corresponded to as 6 primary cutaneous follicle centre lymphoma, large cell cases $(29 \%)$ or to 19 primary cutaneous diffuse large B-cell lymphoma, leg type cases (83\%) (Fig. 1c, d) and such distribution was statistically different $(p=0.006)$

\section{Cytogenetic analysis}

FISH analysis for $B C L 2, B C L 6$, and $M Y C$ was found interpretable in 41 cases because of hybridization failure in 

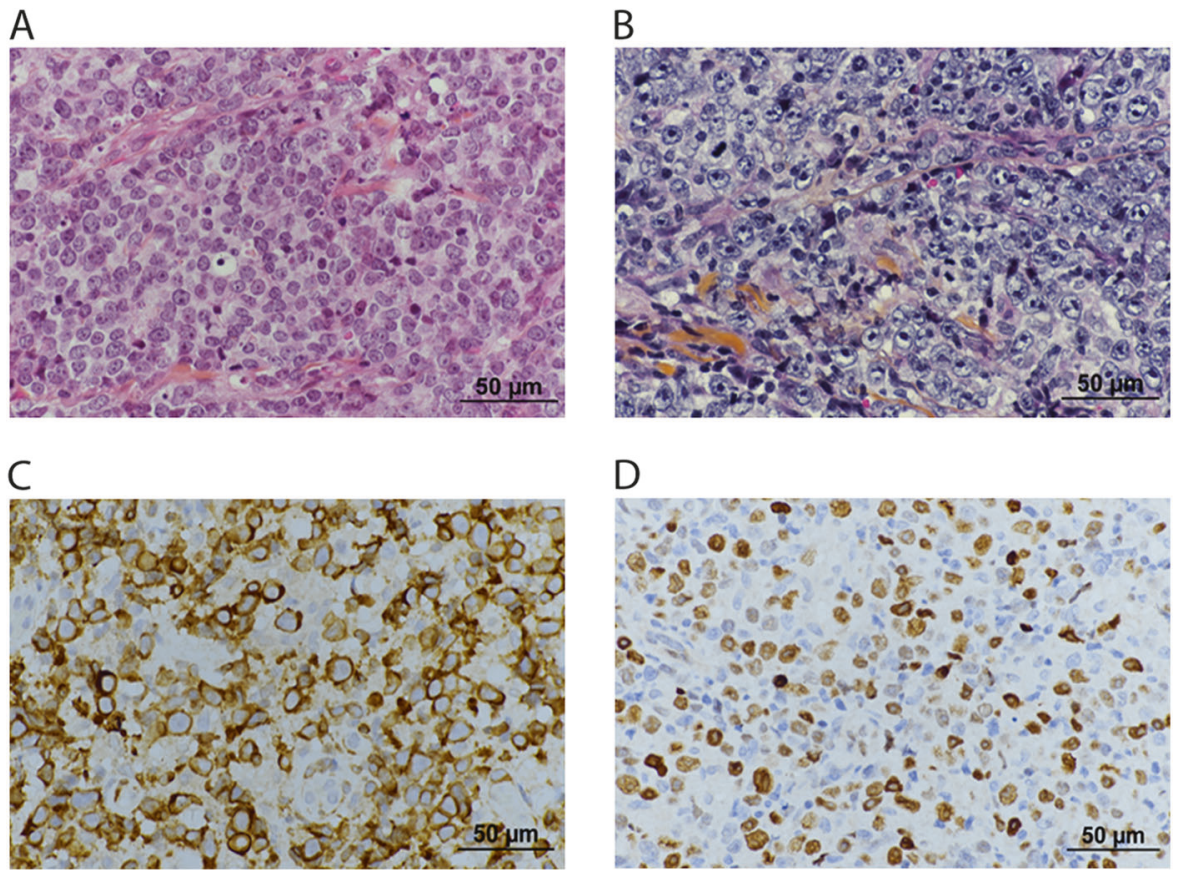

Fig. 1 Histological and phenotype features of primary cutaneous large B-cell lymphoma. a Diffuse infiltration of the dermis by large lymphomatous cells with centroblastic morphology in a case of primary cutaneous follicle centre lymphoma, large cell (Hematoxylin-eosinsaphranin, original magnification $\times 400$ ). b Diffuse infiltration of dermis by large lymphomatous cells with immunoblastic cytology in a

case of primary cutaneous diffuse large B cell lymphoma, leg type (Hematoxylin-eosin-saphranin, original magnification $\times 400$ ). c BCL2 expression in a case of primary cutaneous diffuse large B-cell lymphoma, leg type (original magnification $\times 400$ ). d MYC expression in a case of primary cutaneous diffuse large B-cell lymphoma, leg type (original magnification $\times 400$ )

Fig. 2 Cytogenetic analysis of $B C L 2, B C L 6, M Y C$ by

fluorescent in situ hybridization in primary cutaneous large B-

cell lymphoma. a Split of MYC signals in a case of primary cutaneous diffuse large B-cell lymphoma, leg type. b Split of $B C L 6$ signals in a case of primary cutaneous follicle centre lymphoma large cell. c Amplification of BCL2 locus in a case of primary cutaneous diffuse large B-cell lymphoma, leg type. d Gain of BCL6 locus in a case of primary cutaneous diffuse large B-cell lymphoma, leg type
A

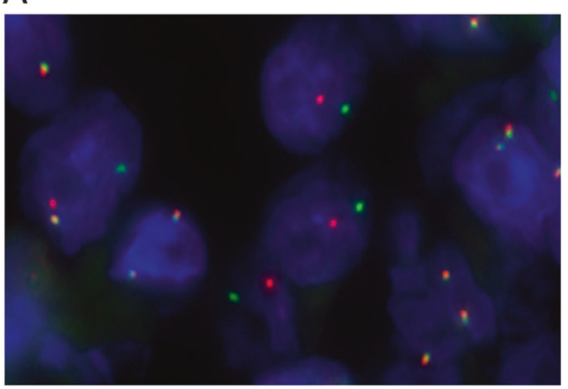

$C$

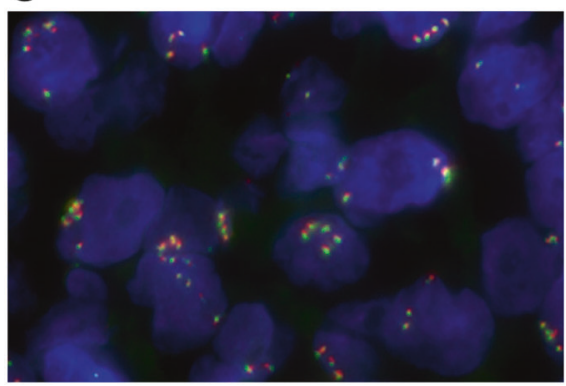

B

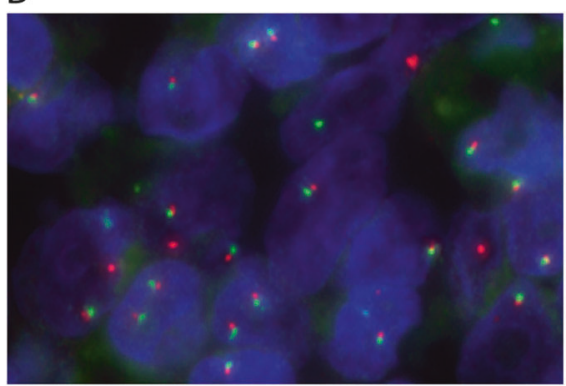

D

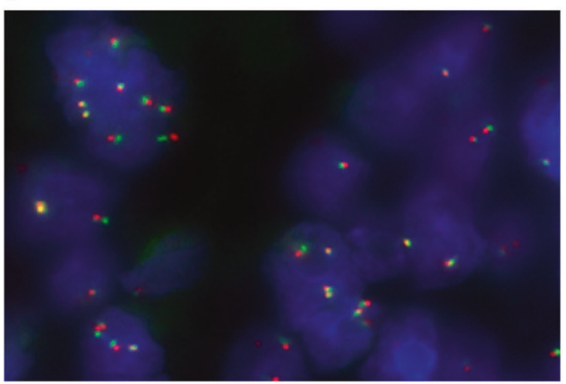

3 cases (Table 2). Concerning MYC, 2 cases (5\%) displayed a rearrangement or hit, 1 primary cutaneous diffuse large Bcell lymphoma, leg type case (5\%) and 1 primary cutaneous follicle centre lymphoma, large cell case (5\%) (Fig. 2a). A low copy-number gain of the $M Y C$ was only observed in 1 primary cutaneous follicle centre lymphoma, large cell case (2\%). A rearrangement of the BCL6 locus was observed in 5 cases (12\%) with 1 primary cutaneous follicle centre 

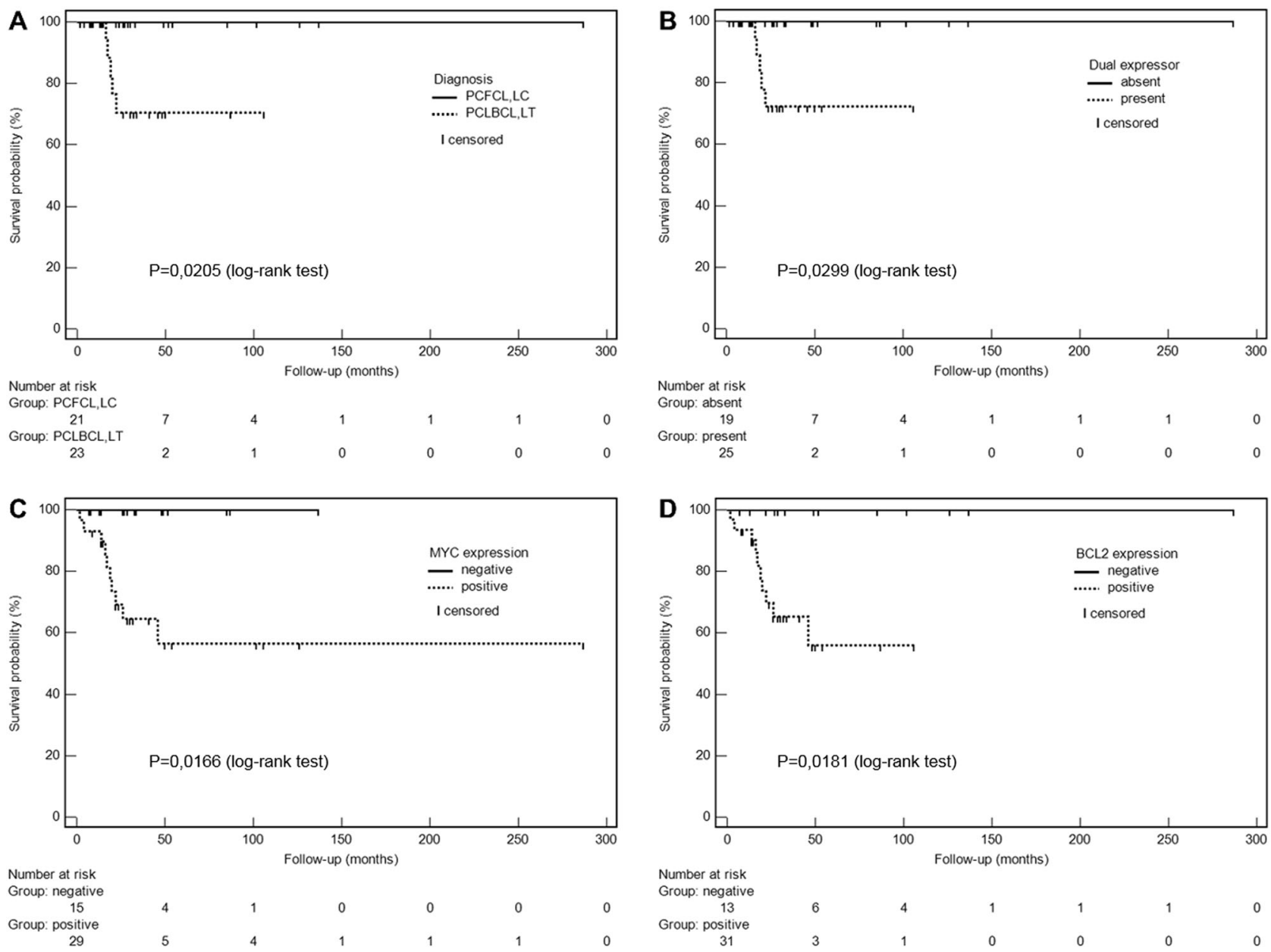

Fig. 3 Survival curves of patients with primary cutaneous large B-cell lymphoma, diagnosed between 1993 and 2016-French Study group on cutaneous lymphoma database, France $(n=44)$. a Specific survival according to histological diagnosis in 21 patients with primary cutaneous follicle centre lymphoma, large cells (PCFCL, LC) and in 23 patients with primary cutaneous large B-cell lymphoma, leg type (PCDLBCL,LT). The global difference between curves was significant $(p=0.021)$. b Specific survival according to MYC and BCL2 dual

lymphoma, large cell case (5\%) and 4 primary cutaneous diffuse large B-cell lymphoma, leg type cases (18\%) (Fig. 2b). A low copy-number gain of the BCL6 locus was identified in 3 primary cutaneous diffuse large B-cell lymphoma, leg type cases (7\%) (Fig. 2d). No BCL2 rearrangement or hit was observed but a low copy-number gain or an amplification of $B C L 2$ were observed in 3 primary cutaneous follicle centre lymphoma cases $(7 \%)$ and in 1 case $(2 \%)$ of primary cutaneous diffuse large B-cell lymphoma, leg type, respectively (Fig. 2c). Only one primary cutaneous large B-cell lymphoma (2\%) displayed a doublehit pattern with translocation of $M Y C$ and BCL6. This case was a primary cutaneous follicle centre lymphoma, large cell which also expressed MYC, BCL2, and BCL6. Two primary cutaneous diffuse large B-cell lymphoma, leg type

expression: no dual expression (19 patients), dual expressor status (25 patients). The global difference between curves was significant $(p=$ 0.030). c Overall survival according to MYC expression: No MYC expression (15 patients) and MYC expression (29 patients). The global difference between curves was significant $(p=0.017)$. d Overall survival according to BCL2 expression: No BCL2 expression (13 patients) and BCL2 expression (31 patients). The global difference between curves was significant $(p=0.018)$

cases (5\%), harbored a double low copy-number gain of $B C L 2$ and BCL6 loci.

Cytogenetic alterations (gain or translocation) of $B C L 6$ were significantly more frequent in primary cutaneous diffuse large B-cell lymphoma, leg-type than in primary cutaneous follicle centre lymphoma, large cell (33 vs. 1.5\%, $p=0.049$ ).

\section{MYD88 status determination}

The MYD88 $8^{\mathrm{L} 265 \mathrm{P}}$ mutation was detected in 16 out of 23 primary cutaneous diffuse large B-cell lymphoma, leg type cases $(70 \%)$ but not in the 21 primary cutaneous follicle centre lymphoma, large cell cases (Table 2). There was no significant correlation between MYD88 status and MYC 


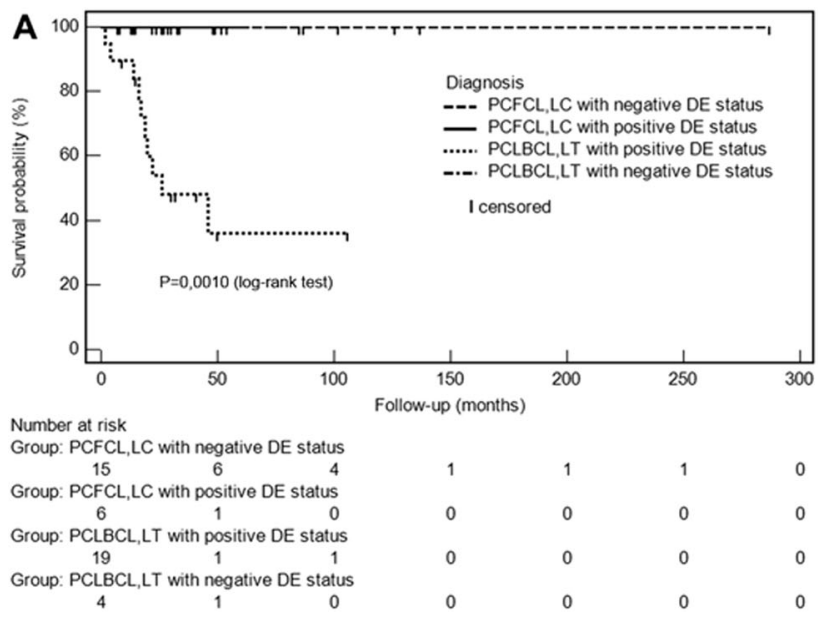

Fig. 4 Survival curves of patients with primary cutaneous large B-cell lymphoma according to the dual expressor (DE) status of MYC and BCL2 (positive or negative) evaluated against the histopathological diagnosis of primary cutaneous follicle centre lymphoma, large cells (PCFCL,LC) and primary cutaneous diffuse large B-cell lymphoma,

expression $(p=0.51)$ and between MYD88 status and dual expressor phenotype $(p=0.113)$.

\section{Survival analysis}

On the whole series of 44 primary cutaneous large B-cell lymphoma cases, the median follow-up was 29 months (range: 2-287). Ten patients (23\%) died during follow-up, all in the subgroup of primary cutaneous diffuse large B-cell lymphoma, leg type. The death was related to the disease in 5 patients $(11 \%)$. Eighteen patients out of $44(40 \%)$ exhibited cutaneous relapses and $8(18 \%)$ had extracutaneous spreading. The median overall survival was not reached and median progression free survival was 41 months.

Overall survival and specific survival were significantly worse in primary cutaneous diffuse large B-cell lymphoma, leg type than in primary cutaneous follicle centre lymphoma, large cell ( $p=0.001$ and $p=0.021$, respectively) (Fig. 3a). Progression free survival was not different between the two histological subgroups $(p=0.722)$.

According to MYC and BCL2 expression profile, the dual expressor group showed a worse overall survival $(p=$ $0.002)$ and a worse specific survival $(p=0.030)$ (Fig. 3b). Expression of MYC was associated with a worse overall survival $(p=0.017)$ (Fig. 3c). Similarly, expression of BCL2 was associated with a worse overall survival ( $p=$ 0.018) (Fig. 3d).

Concerning cytogenetic results, BCL6 cytogenetic alterations (gain and translocation) significantly affected negatively specific survival $(p=0.024)$ but not overall survival $(p=0.379)$. There was a non-significant trend for a worse prognosis in patients with $B C L 6$ translocation $(p=$

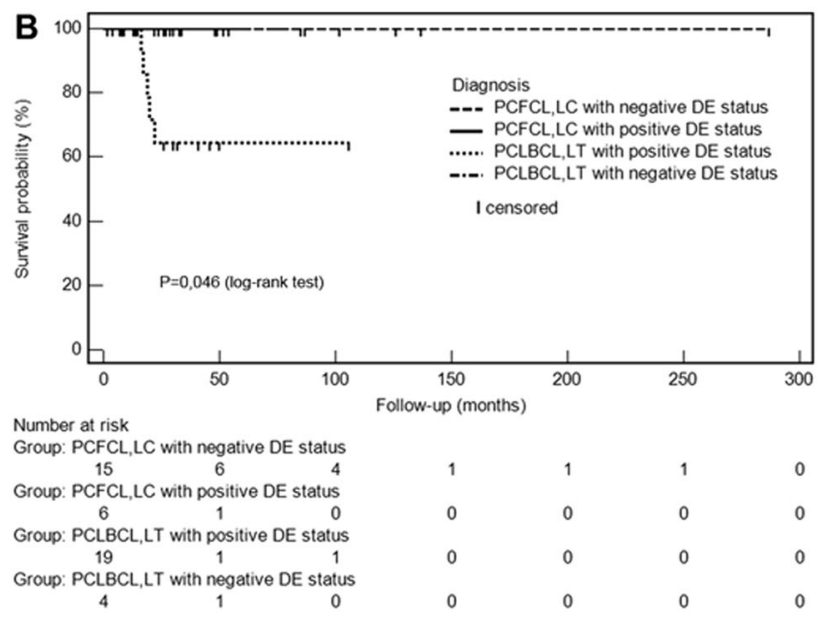

leg type (PCLBCL,LT). The dual expressor primary cutaneous diffuse large B-cell lymphoma, leg type subgroup had a significant worse overall survival (a) and specific survival (b) $(p=0.001$ and $p=0.046$, respectively)

0.086). $M Y C$ or $B C L 2$ cytogenetic alterations did not significantly impact overall survival $(p=0.56$ and $p=0.525$, respectively).

In the subgroup of primary cutaneous follicle centre lymphoma, large cell, overall survival or specific survival were not a workable factor because all patients were alive at end point. Nine patients (43\%) harbored cutaneous relapses and extracutaneous progression concerned 2 patients (9\%). Median progression free survival was 131 months.

In the subgroup of primary cutaneous diffuse large B-cell lymphoma, leg type, median overall survival was 46 months. Nine patients (40\%) harbored cutaneous relapses. Extra-cutaneous progression concerned 6 patients (26\%). Median progression free survival was 32 months. Overall survival seemed to be negatively influenced by dual expression profile in our limited cohort $(p=0.099)$. The single criterion affecting overall survival was MYC expression.

When analyzing survival according to both the histopathological diagnosis and the dual expressor status, the subgroup of dual expressor primary cutaneous diffuse large B-cell lymphoma, leg type displayed a significant worse overall survival $(p=0.001)$ and specific survival $(p=$ 0.046) than each of the three other groups (Fig. 4). Indeed, all deaths were observed in this specific subgroup.

\section{Discussion}

Owing to the difficulty in the differential diagnosis between primary cutaneous follicle centre lymphoma, large-cell and primary cutaneous large B-cell lymphoma leg type which has major impact, we have evaluated on a retrospective 
series of 44 typical primary cutaneous large B-cell lymphoma cases the new criteria used for nodal diffuse large Bcell lymphoma categorization to define double-hit of $M Y C$ and $B C L 2$ and/or BCL6 genes rearrangement or the dual expression of MYC and BCL2 proteins. The series corresponded to cases that were prospectively included in our national database with standardized criteria for diagnosis, staging and follow-up. Neither secondary skin involvement by systemic lymphoma nor primary cutaneous follicle centre lymphoma small cell was included as they do not raise the diagnosis and therapeutic issues of primary cutaneous large B-cell lymphoma. Beyond the identification of double-hit or dual expressor cases, we measured the diagnostic relevance and impact on prognosis of such categorization of primary cutaneous large B-cell lymphoma.

One main finding of our study is that double-hit primary cutaneous large B-cell lymphoma is extremely rare as it was observed in a single patient with primary cutaneous follicle centre lymphoma, large cell who is still alive with complete response after 29 months' follow-up. Our findings are in accordance with partial data of other groups evaluating the status of MYC, BCL2, or BCL6 locus in a various set of primary cutaneous B-cell lymphoma mixing cases with either small-cell or large-cell morphology [6, 28, 31-34]. Therefore, our study would not support the evaluation of double-hit in primary cutaneous large B-cell lymphoma as opposed to the recommendation for nodal diffuse large B-cell lymphoma [2].

Moreover, we did not find any $B C L 2$ rearrangement in both primary cutaneous follicle centre lymphoma, large cell or primary cutaneous diffuse large B-cell lymphoma, leg type as generally observed [32, 35]. Other studies including one from our group observed a low rate of $B C L 2$ rearrangement in primary cutaneous follicle centre lymphoma $[6$, 36, 37]. MYC was found rearranged in rare cases of either primary cutaneous follicle centre lymphoma, large cell or primary cutaneous diffuse large B-cell lymphoma, leg type subtype. As reported previously [7, 29], BCL6 cytogenetic alterations were slightly more frequent in primary cutaneous diffuse large B-cell lymphoma, leg type cases than in primary cutaneous follicle centre lymphoma, large cell but such event is too rare to be used for differential diagnosis between the two entities. As opposed to their impact in nodal diffuse large B-cell lymphoma [38-42], no impact on primary cutaneous large B-cell lymphoma prognosis was found for most of the cytogenetic alterations including double-hit, single hit or abnormality of MYC or BCL2. Only a non-significant trend for a worse prognosis of primary cutaneous large B-cell lymphoma was observed with an abnormal BCL6 status (split or gain), as already reported in a series of nodal diffuse large B-cell lymphoma [43]. However, neither $B C L 6$ translocation alone nor double-hit involving $M Y C$ and $B C L 6$ were found to predict poorer outcome in another large series of 898 diffuse large B-cell lymphoma cases [44]. In primary cutaneous large B-cell lymphoma, the relevance of single hit or double-hit evaluation will remain elusive as such event is too occasional in such rare disease.

Alternatively, our study brings up that determination of the dual expressor status (MYC and BCL2) has impact on both diagnosis and prognosis. Indeed, MYC expression has not been investigated routinely in primary cutaneous diffuse large B-cell lymphoma, leg type which usually express BCL2. Dual expressor-primary cutaneous large B-cell lymphoma represent nearly $60 \%$ of cases but was more frequently seen in primary cutaneous diffuse large B-cell lymphoma, leg type $(83 \%)$ than in primary cutaneous follicle centre lymphoma, large cell (29\%). The single expression of MYC or BCL2 and the dual expressor status were associated with an inferior outcome in primary cutaneous large B-cell lymphoma, as recently reported for MYC in primary cutaneous diffuse large B-cell lymphoma, legtype [45]. The expression of BCL2 is already used as an immunohistochemical criterion for primary cutaneous diffuse large B-cell lymphoma, leg type diagnosis [3, 16, 18, 46]. The altered prognosis of patients with dual expression was found significant at the level of the entire primary cutaneous large B-cell lymphoma cohort but also in the primary cutaneous diffuse large B-cell lymphoma, leg type subgroup as patients with dual expression had the most aggressive disease.

A single study has previously reported that MYC and BCL2 co-expression in primary cutaneous B-cell lymphoma may impact overall survival and progression free survival [6]. They individualized, a third separate category of primary cutaneous large B-cell lymphoma, previously named primary cutaneous diffuse large B-cell lymphoma, not otherwise specified [8], according to its intermediate prognosis between primary cutaneous follicle centre lymphoma and primary cutaneous diffuse large B-cell lymphoma, leg type [6]. Such study however differs from ours as it focused on the impact on prognosis of the immunohistochemical Hans' algorithm which had practical limitations as $20 \%$ of primary cutaneous diffuse large B-cell lymphoma, leg type displayed a paradoxical germinal centre profile [6]. A prognostic value of $B C L 2$ rearrangement was also found that contrasts with its absence in our series suggesting heterogeneity in inclusion criteria. Alternatively, our findings are in agreement with the EORTC and WHO classification considering primary cutaneous follicle centre lymphoma, large cell as a subtype of primary cutaneous follicle centre lymphoma [2,9]. In our study, all patients with primary cutaneous follicle centre lymphoma, large cell subgroup displayed a very good prognosis which was statistically different from that of primary cutaneous diffuse large B-cell lymphoma, leg type. 
For primary cutaneous large B-cell lymphoma, the histological categorization into two separate subgroups has a major impact for the management of patients making the pathologist's decision a crucial issue. Ancillary testing such as the detection of the MYD88 ${ }^{\mathrm{L} 265 \mathrm{P}}$ mutation may help pathologists to confirm the diagnosis of primary cutaneous diffuse large B-cell lymphoma, leg type [18]. Our study would suggests that MYC immunostaining could be added to those of BCL2 and MUM1 for the diagnosis of primary cutaneous diffuse large B-cell lymphoma, leg type as dual expression of MYC and BCL2 was significantly predominant in this lymphoma subtype. Investigating the mutational profile of 28 primary cutaneous diffuse large B-cell lymphoma, leg type, we recently reported $M Y C$ mutation in about $20 \%$ of cases which also supports a $M Y C$-driven oncogenesis [47].

Our pilot study performed on typical primary cutaneous large B-cell lymphoma cases needs to be confirmed on larger validation sets of patients in order to determine if dual-expression or single MYC expression represent new prognostic factors in multivariate analysis. This will require standardization of diagnostic criteria between primary cutaneous follicle centre lymphoma, large cell and primary cutaneous diffuse large B-cell lymphoma, leg type using consensus immunohistochemical algorithms and/or ancillary molecular testing. Conversely to nodal diffuse large Bcell lymphoma, our study does not argue for the need of double-hit determination in primary cutaneous large B-cell lymphoma. Dual-expressor status was found as a differential diagnosis criterion for primary cutaneous diffuse large B-cell lymphoma, leg type vs. primary cutaneous follicle centre lymphoma, large cell but also identified among patients with primary cutaneous diffuse large B-cell lymphoma, leg type those with the most impaired prognosis.

Acknowledgements We acknowledge the contribution of the following dermatologists and pathologists of the French Study group on Cutaneous Lymphomas for providing clinical data and participating to the review of cutaneous B-cell lymphoma cases included in the database: Brigitte Balme (CHU Lyon, Lyon, France), Valérie CostesMartineau et Vanessa Szablewski (CHU Montpellier, Montpellier, France), Maxime Battistella (Hôpital Saint-Louis, APHP, Paris 10, France), Laurence Lamant et Emilie Tournier (CHU Toulouse, Toulouse, France), Marie-Hélène Lorton (CHU Dijon, Dijon, France), François Comoz (CHU Caen, Caen, France), and Anne de Muret (CHU Tours, Tours, France).

Funding SM was supported by a grant from the Fondation pour la Recherche Médicale. This project was partly supported by a grant from the Société Française de Dermatologie number 06/2016 and by the Program Hospitalier de Recherche Clinique from the French National Cancer Institute INCa number 11-6236.

\section{Compliance with ethical standards}

Conflict of interest The authors declare that they have no conflict of interest.

\section{References}

1. Willemze R, Jaffe ES, Burg G, et al. WHO-EORTC classification for cutaneous lymphomas. Blood. 2005;105:3768-85.

2. Swerdlow SH, Campo E, Pileri SA, et al. The2016 revision of the World Health Organization classification of lymphoid neoplasms. Blood. 2016;127:2375-90.

3. Senff NJ, Noordijk EM, Kim YH, et al. European organization for research and treatment of cancer and international society for cutaneous lymphoma consensus recommendations for the management of cutaneous B-cell lymphomas. Blood. 2008;112:1600-9.

4. Grange F, Joly P, Barbe C, et al. Improvement of survival in patients with primary cutaneous diffuse large B-cell lymphoma, leg type, in France. JAMA Dermatol. 2014;150:535-41.

5. Zinzani PL, Quaglino P, Pimpinelli N, et al. Prognostic factors in primary cutaneous B-cell lymphoma: the Italian study group for cutaneous lymphomas. J Clin Oncol. 2006;24:1376-82.

6. Lucioni M, Berti E, Arcaini L, et al. Primary cutaneous B-cell lymphoma other than marginal zone: clinicopathologic analysis of 161 cases: Comparison with current classification and definition of prognostic markers. Cancer Med. 2016;5:2740-55.

7. Plaza JA, Kacerovska D, Stockman DL, et al. The histomorphologic spectrum of primary cutaneous diffuse large B-cell lymphoma: a study of 79 cases. Am J Dermatopathol. 2011;33:649-58.

8. Kodama K. Primary cutaneous large B-cell lymphomas: clinicopathologic features, classification, and prognostic factors in a large series of patients. Blood. 2005;106:2491-7.

9. Senff NJ, Hoefnagel JJ, Jansen PM, et al. Reclassification of 300 primary cutaneous B-cell lymphomas according to the new WHO-EORTC classification for cutaneous lymphomas: comparison with previous classifications and identification of prognostic markers. J Clin Oncol. 2007;25:1581-7.

10. Hans CP. Confirmation of the molecular classification of diffuse large B-cell lymphoma by immunohistochemistry using a tissue microarray. Blood. 2004;103:275-82.

11. Alizadeh AA, Eisen MB, Davis RE, et al. Distinct types of diffuse large B-cell lymphoma identified by gene expression profiling. Nature. 2000;403:503-11.

12. Rosenwald A, Wright G, Chan WC, et al. The use of molecular profiling to predict survival after chemotherapy for diffuse largeB-cell lymphoma. N Engl J Med. 2002;346:1937-47.

13. Hoefnagel JJ. Distinct types of primary cutaneous large B-cell lymphoma identified by gene expression profiling. Blood. 2005;105:3671-8.

14. Mitteldorf C, Berisha A, Pfaltz MC, et al. Tumor microenvironment and checkpoint molecules in primary cutaneous diffuse large B-cell lymphoma-New therapeutic targets. Am J Surg Path. 2017;41:998-1004.

15. Xie X, Sundram U, Natkunam Y, et al. Expression of HGAL in primary cutaneous large B-cell lymphomas: evidence for germinal centre derivation of primary cutaneous follicular lymphoma. Mod Pathol. 2008;21:653-9.

16. Dewar R, Andea AA, Guitart J, et al. Best practices in diagnostic immunohistochemistry: workup of cutaneous lymphoid lesions in the diagnosis of primary cutaneous lymphoma. Arch Pathol Lab Med. 2015;139:338-50.

17. Swerdlow SH, Quintanilla-Martinez L, Willemze R, et al. Cutaneous B-cell lymphoproliferative disorders: report of the 2011 society for hematopathology/European association for haematopathology workshop. Am J Clin Pathol. 2013;139:515-35.

18. Menguy S, Gros A, Pham-Ledard A, et al. MYD88 somatic mutation is a diagnostic criterion in primary cutaneous large B-cell lymphoma. J Invest Dermatol. 2016;136:1741-4. 
19. Robson A, Shukur Z, Ally M, et al. Immunocytochemical p63 expression discriminates between primary cutaneous follicle centre cell and diffuse large B cell lymphoma-leg type, and is of the TAp63 isoform. Histopathology. 2016;69:11-19.

20. Johnson NA, Savage KJ, Ludkovski O, et al. Lymphomas with concurrent BCL2 and MYC translocations: the critical factors associated with survival. Blood. 2009;114:2273-9.

21. Aukema SM, Siebert R, Schuuring E, et al. Double-hit B-cell lymphomas. Blood. 2011;117:2319-31.

22. Li S, Desai P, Lin P, et al. MYC/BCL6 double-hit lymphoma (DHL): a tumour associated with an aggressive clinical course and poor prognosis. Histopathology. 2016;68:1090-8.

23. Sesques P, Johnson NA. Approach to the diagnosis and treatment of high-grade B-cell lymphomas with MYC and BCL2 and/or BCL6 rearrangements. Blood. 2017;129:280-8.

24. Johnson NA, Slack GW, Savage KJ, et al. Concurrent expression of MYC and BCL2 in diffuse large B-cell lymphoma treated with rituximab plus cyclophosphamide, doxorubicin, vincristine, and prednisone. J Clin Oncol. 2012;30:3452-9.

25. Green TM, Young $\mathrm{KH}$, Visco $\mathrm{C}$, et al. Immunohistochemical double-hit score is a strong predictor of outcome in patients with diffuse large B-cell lymphoma treated with Rituximab plus Cyclophosphamide, Doxorubicin, Vincristine, and Prednisone. J Clin Oncol. 2012;30:3460-7.

26. Savage KJ, Slack GW, Mottok A, et al. Impact of dual expression of MYC and BCL2 by immunohistochemistry on the risk of CNS relapse in DLBCL. Blood. 2016;127:2182-8.

27. $\mathrm{Hu} \mathrm{S}, \mathrm{Xu}-$ Monette ZY, Tzankov A, et al. MYC/BCL2 protein coexpression contributes to the inferior survival of activated B-cell subtype of diffuse large B-cell lymphoma and demonstrates high-risk gene expression signatures: a report from the international DLBCL Rituximab-CHOP consortium program. Blood. 2013;121:4021-31.

28. Pham-Ledard A, Prochazkova-Carlotti M, Andrique L, et al. Multiple genetic alterations in primary cutaneous large B-cell lymphoma, leg type support a common lymphomagenesis with activated B-cell-like diffuse large B-cell lymphoma. Mod Pathol. 2014;27:402-11.

29. Kim YH, Willemze R, Pimpinelli N, et al. TNM classification system for primary cutaneous lymphomas other than mycosis fungoides and Sezary syndrome: a proposal of the international society for cutaneous lymphomas (ISCL) and the cutaneous lymphoma task force of the european organization of research and treatment of cancer (EORTC). Blood. 2007;110:479-84.

30. Pham-Ledard A, Beylot-Barry M, Barbe C, et al. High frequency and clinical prognostic value of MYD88 L265P mutation in primary cutaneous diffuse large B-cell lymphoma, leg-type. JAMA Dermatol. 2014;150:1173-9.

31. Hallermann C, Kaune KM, Gesk S, et al. Molecular cytogenetic analysis of chromosomal breakpoints in the IGH, MYC, BCL6, and MALT1 gene loci in primary cutaneous B-cell lymphomas. J Invest Dermatol. 2004;123:213-9.

32. Hallermann C, Kaune KM, Siebert R, et al. Chromosomal aberration patterns differ in subtypes of primary cutaneous $\mathrm{B}$ cell lymphomas. J Invest Dermatol. 2004;122:1495-502.

33. Tsang HC, Mathew S, Magro CM. An aggressive primary cutaneous follicle centre lymphoma with c-MYC translocation and CDKN2A (9p21) deletion: a case report and review of the literature. Amn J Dermatopathol. 2017;39:e44-9.
34. Wiesner T, Streubel B, Huber D, et al. Genetic aberrations in primary cutaneous large B-cell lymphoma: a fluorescence in situ hybridization study of 25 cases. Am J Surg Pathol. 2005;29:666-73.

35. Vergier B, Belaud-Rotureau M-A, Benassy M-N, et al. Neoplastic cells do not carry bcl2-JH rearrangements detected in a subset of primary cutaneous follicle centre B-cell lymphomas. Am J Surg Pathol. 2004;28:748-55.

36. Pham-Ledard A, Cowppli-Bony A, Doussau A, et al. Diagnostic and prognostic value of BCL2 rearrangement in 53 patients with follicular lymphoma presenting as primary skin lesions. Am J Clin Pathol. 2015;143:362-73.

37. Szablewski V, Ingen-Housz-Oro S, Baia M, et al. Primary cutaneous follicle centre lymphomas expressing BCL2 protein frequently harbor BCL2 gene break and may present 1p36 deletion: a study of 20 cases. Am J Surg Pathol. 2016;40:127-36.

38. Klapper W, Stoecklein H, Zeynalova S, et al. Structural aberrations affecting the MYC locus indicate a poor prognosis independent of clinical risk factors in diffuse large B-cell lymphomas treated within randomized trials of the German high-grade nonHodgkin's lymphoma study group (DSHNHL). Leukemia. 2008;22:2226-9.

39. Savage KJ, Johnson NA, Ben-Neriah S, et al. MYC gene rearrangements are associated with a poor prognosis in diffuse large B-cell lymphoma patients treated with R-CHOP chemotherapy. Blood. 2009;114:3533-7.

40. Barrans S, Crouch S, Smith A, et al. Rearrangement of MYC is associated with poor prognosis in patients with diffuse large B-cell lymphoma treated in the era of Rituximab. J Clin Oncol. 2010;28:3360-5.

41. Lin P, Dickason TJ, Fayad LE, et al. Prognostic value of MYC rearrangement in cases of B-cell lymphoma, unclassifiable, with features intermediate between diffuse large B-cell lymphoma and Burkitt lymphoma. Cancer. 2012;118:1566-73.

42. Quesada AE, Medeiros LJ, Desai PA, et al. Increased MYC copy number is an independent prognostic factor in patients with diffuse large B-cell lymphoma. Mod Pathol. 2017;30:1688-97.

43. Copie-Bergman C, Gaulard P, Leroy K, et al. Immuno-fluorescence in situ hybridization index predicts survival in patients with diffuse large B-cell lymphoma treated with RCHOP: a GELA study. J Clin Oncol. 2009;27:5573-9.

44. Ye Q, Xu-Monette ZY, Tzankov A, et al. Prognostic impact of concurrent MYC and BCL6 rearrangements and expression in de novo diffuse large B-cell lymphoma. Oncotarget. 2016;7:2401-16.

45. Kim YJ, Won $\mathrm{CH}$, Chang SE, et al. MYC protein expression is associated with poor prognosis in cutaneous diffuse large B-cell lymphoma. Australasian J Dermatol. https://doi.org/10.1111/ajd. 12705.

46. Hoefnagel JJ, Vermeer MH, Jansen PM, et al. Bcl-2, Bcl-6 and CD10 expression in cutaneous B-cell lymphoma: further support for a follicle centre cell origin and differential diagnostic significance. Br J Dermatol. 2003;149:1183-91.

47. Mareschal S, Pham-Ledard A, Viailly PJ, et al. Identification of somatic mutations in primary cutaneous diffuse large B-cell lymphoma, leg-type by massive parallel sequencing. J Invest Dermatol. 2017;137:1984-94. 